\title{
Classification of Tumors of the Hematopoietic and Lymphoid Tissues. Discovering Diseases-Defining Their Features ${ }^{\dagger}$
}

\author{
Antonino Carbone \\ Professor of Pathology, Former Chairman of Department of Pathology, Centro di Riferimento Oncologico (CRO), \\ National Cancer Institute, Via Franco Gallini 2, 33081 Aviano, Italy; acarbone@cro.it \\ + This Editorial has been prepared with the assistance of the Managing Editor (Carey Yuan).
}

Received: 8 May 2020; Accepted: 12 May 2020; Published: 13 May 2020

The World Health Organization (WHO) Classification of Tumours of the Hematopoietic and Lymphoid Tissues [1-3], in the 3rd Edition published in 2001 and the 4th Edition Bluebooks of 2008 and 2017, has helped to build an international consensus among pathologists, hematologists, radiologists, and clinical oncologists. WHO classification has helped to define multiple entities using the principles of the REAL classification [4], incorporating morphology, immunophenotyping, genomics, and clinical features. These reference volumes for the histopathological classification of lymphoid tumors also present concise information on each tumor's epidemiology, clinical and imaging findings, risk factors, and prognosis as a guide for their diagnosis.

\section{Disease Discovery and Disease Definition}

It seems appropriate to describe the understanding of the disease model applied in the WHO Classification of Tumours as applicable to research. This model, extrapolated from consideration of Dr. Jaffe, starts from clinical observation, and throughout the pathogenetic study, has clear effects in terms of diagnosis, prognosis, and treatment [5]. Disease discovery and disease definition using the microscope as a tool on tumor tissue sections are critical first steps in elucidating the pathogenesis of lymphomas. Knowledge of molecular pathogenesis and discovery of recurrent genetic alterations have usually been followed a precise description of the lymphoma entity based on clinical, morphological, or immunophenotypic grounds (Figure 1). On the other hand, molecular pathogenetic studies on tumor-derived DNA/RNA are critical steps in elucidating the pathogenetic mechanisms underlying the development of a lymphoma. This knowledge leads to a precise diagnosis due to understanding of morphologic features, biological aggressiveness, and clinical behavior, and guides the therapeutic strategy. To quote Dr. Jaffe, "The discovery of the disease nearly always precedes the discovery of gene. However, the process is iterative such that knowledge of the genetic pathogenesis provides new diagnostic tools, which help define the disease and its borderlands" (Figure 1) [5]. 


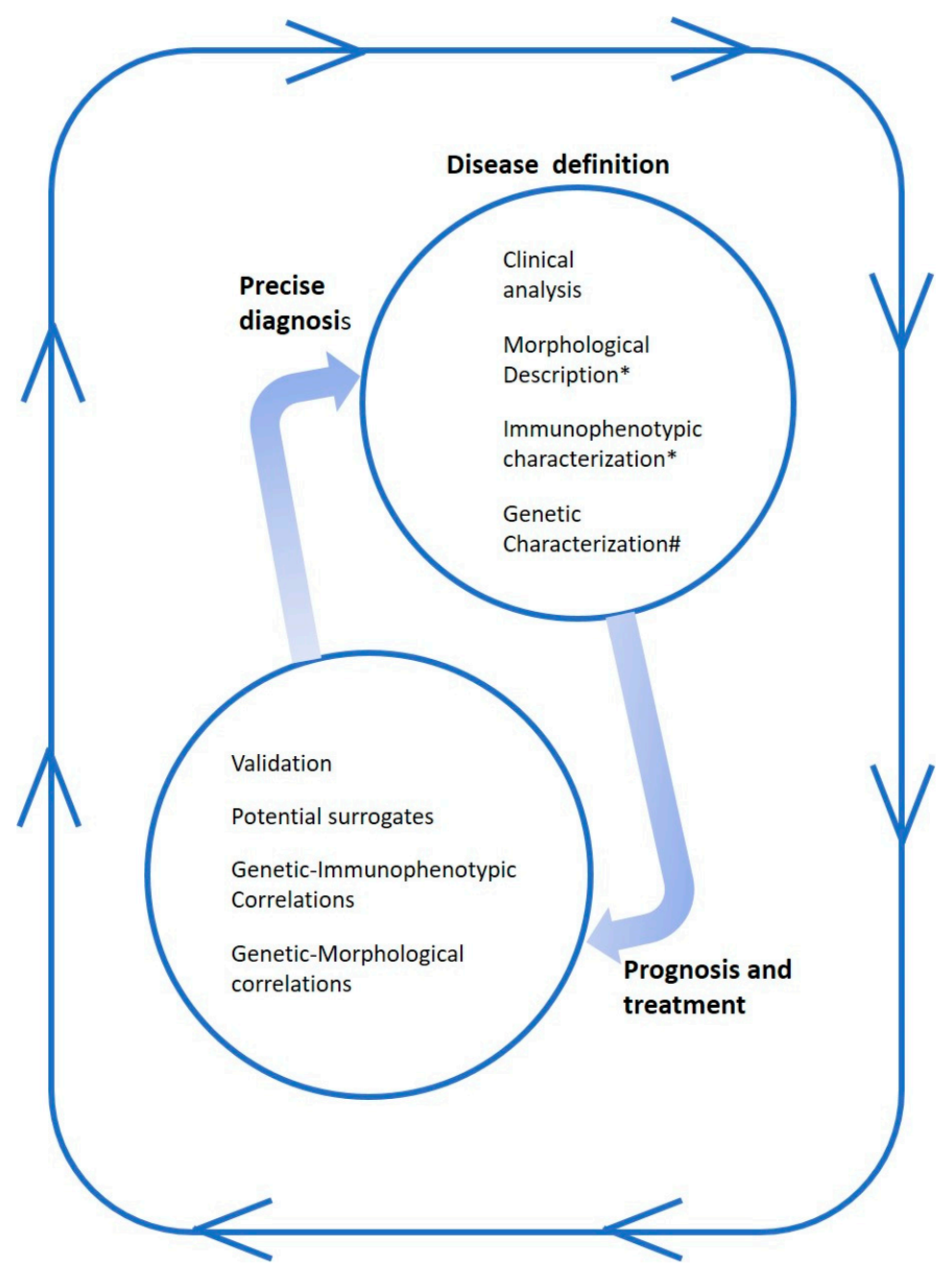

Figure 1. Understanding of disease. The figure shows the necessary steps for disease definition, which indicate the prognosis and guide the treatment. Other steps using pathogenetic information and searching valid surrogates may be helpful to reach a precise diagnosis using the microscope as a tool. * Tumor cells and tumor microenvironment in tissue sections; \# Translocation; gene mutation; clonality; oncogenic pathways analyzed in extracted nucleic acids.

This model has been applied in understanding, for example, mantle cell lymphoma and peripheral T-cell lymphoma, not otherwise specified. Mantle cell lymphoma, initially recognized on morphologic grounds, was termed using different names according to the morphotype of proliferating cells. Subsequently, it was related to the lymphocyte cuff of lymphoid follicle mantle according to the phenotypic properties of tumor cells. Later on, the lymphoma was linked to CCND1/BCL1 translocation, facilitating its accurate definition [6]. Another example is the case of peripheral T-cell lymphomas not otherwise specified (NOS). This group of lymphomas is heterogeneous, and has been termed NOS or undetermined because precise morphological subgroups cannot be identified within it. These lymphomas have recently been subclassified into two subgroups with distinct prognoses on the basis of gene and protein expression profiles [7]. Thus, molecular information is helping to distinguish tumors into subgroups for which different treatments can be developed [7]. Histopathological classification and molecular genetic profiling of lymphomas can be used together in choosing the treatment strategy.

Conflicts of Interest: The author declares no conflict of interest. 


\section{References}

1. Jaffe, E.S.; Harris, N.L.; Stein, H.; Vardiman, J.W. (Eds.) World Health Organization Classification of Tumours, Pathology and Genetics of Tumours of Haematopoietic and Lymphoid Tissues; IARC Press: Lyon, France, 2001.

2. Swerdlow, S.H.; Campo, E.; Harris, N.L.; Jaffe, E.S.; Pileri, S.A.; Stein, H.; Thiele, J.; Vardiman, J.W. (Eds.) WHO Classification of Tumours of Haematopoietic and Lymphoid Tissues, 4th ed.; IARC: Lyon, France, 2008.

3. Swerdlow, S.H.; Campo, E.; Harris, N.L.; Jaffe, E.S.; Pileri, S.A.; Stein, H.; Thiele, J. (Eds.) WHO Classification of Tumours of Haematopoietic and Lymphoid Tissues, Revised 4th ed.; IARC: Lyon, France, 2017.

4. Harris, N.L.; Jaffe, E.S.; Stein, H.; Banks, P.M.; Chan, J.K.; Cleary, M.L. A revised European-American classification of lymphoid neoplasms: A proposal from the International Lymphoma Study Group. Blood 1994, 84, 1361-1392. [CrossRef]

5. Jaffe, E.S. The microscope as a tool for disease discovery-A personal voyage. Annu. Rev. Pathol. Mech. Dis. 2017, 12, 1-24. [CrossRef] [PubMed]

6. Campo, E.; Raffeld, M.; Jaffe, E.S. Mantle-cell lymphoma. Semin Hematol. 1999, 36, 115-127. [PubMed]

7. Amador, C.; Greiner, T.; Heavican, T.B.; Smith, L.M.; Galvis, K.T.; Lone, W.G.; Bouska, A.; D'Amore, F.; Pedersen, M.B.; Pileri, S.A.; et al. Reproducing the molecular subclassification of peripheral T-cell lymphoma-NOS by immunohistochemistry. Blood 2019, 134, 2159-2170. [CrossRef] [PubMed]

(C) 2020 by the author. Licensee MDPI, Basel, Switzerland. This article is an open access article distributed under the terms and conditions of the Creative Commons Attribution (CC BY) license (http://creativecommons.org/licenses/by/4.0/). 